\title{
Engineering models for the design of long-lasting, sustainable, cost-efficient and climate-responsive pavements for Ashghal road projects in the State of Qatar
}

\author{
Ezio SANTAGATA, Politecnico di Torino, Turin, Italy \\ Lucia TSANTILIS, Politecnico di Torino, Turin, Italy \\ Ilaria BRIGNONE AIMONETTO, ANAS s.p.a., Qatar Branch, Lusail, Qatar \\ Marco MARCHIANDO, ANAS s.p.a., Qatar Branch, Lusail, Qatar \\ Osman Elhusain Mohamed IDRIS, Quality and Safety Department, Public Works Authority, Doha, Qatar \\ Moaaz Hashim M.M. ALI, Quality and Safety Department, Public Works Authority, Doha, Qatar \\ Ali Mohammed AL-MARRI, Quality and Safety Department, Public Works Authority, Doha, Qatar
}

\begin{abstract}
The planning, design, construction and management of modern transportation infrastructures is based on the use of continuously updated methodologies that consider, among others, the concept of sustainability. In such a context, for the specific case of road pavements, it is of crucial importance to carry out quantitative analyses based on the use of optimized engineering models. These models explicitly consider environment-pavement interactions, environmental impacts generated by all the components involved in the supply chain, and financial flows associated to pavement construction and maintenance. Such an approach is being adopted by the Public Works Authority (Ashghal) of the State of Qatar, that is developing and implementing models tailored for its infrastructure projects and local environmental conditions. This paper provides an overview of some of the employed models and methodologies that are based on the physics of pavement structures and on the assessment of environmental and economic indicators. It is shown that such an approach leads to significant improvements to current practice and to the enhanced use of recycled materials, while still guaranteeing required pavement performance.
\end{abstract}

\section{Keywords}

Pavements, Modelling, Temperature, Life cycle analysis, Life cycle cost analysis, Recycling

\section{Introduction}

Transportation infrastructures are key components of the modern highly interconnected urban built environment. As such, their planning, design, construction and management is based on the use of methodologies that are continuously updated to address the everchanging challenges that originate from the evolution of mobility demand, environmental conditions, availability of resources and end-user expectations. Furthermore, stimuli for improvement are nowadays also originated in the context of a "post-oil era" vision, in which one of the main driving forces of development is represented by sustainability (Pasetto et al., 2019). 
Santagata, E.; Tsantilis, L.; Brignone Aimonetto, I.; Marchiando, M.; Idris, O.E.M.; Ali, M.H.M.M.; Al-Marri, A.M.
Engineering models for the design of long-lasting, sustainable, cost-efficient and climate-responsive pavements for Ashghal road projects in Qatar

In the specific case of road pavements, sustainability can be addressed by moving away from standard materials and cross-sections, thereby making use of local and recycled materials and of innovative technological solutions. These need to be identified and tailored with the purpose of guaranteeing a longlasting service life, a sufficiently low life-cycle environmental impact, and an adequate overall long-term economic efficiency (Huang et al., 2007). Furthermore, in densely populated urban centres located in geographical areas characterized by a hot and arid climate, sustainable road pavements need also to contribute to the prevention of urban heat island effects (Shandas et al., 2020).

The abovementioned goals can be achieved by means of quantitative analyses based on the use of optimized engineering models that explicitly consider environment-pavement interactions, the financial flow associated to pavement construction and maintenance, and the environmental impacts generated by all the components involved in the supply chain. Such an approach has been in recent times adopted by the Public Works Authority (Ashghal) of the State of Qatar through the activities of its Departments and by means of focused collaborations with industrial and academic partners. In particular, relevant results have been obtained in the "QA/QC Pavement Consultancy Services" project locally developed by ANAS S.p.A. (Italy) since 2012. Since 2017 the project has been coordinated by the Quality \& Safety Department (QSD) of Ashghal.

This paper provides an outline of the engineering models that can be adopted for Ashghal pavement projects. Depending upon the case they are based on the physics of pavement structures - for the evaluation of heat transfer and response under traffic loading - or on the assessment of environmental and economic indicators - typically included in pavement evaluation processes for life cycle assessment (LCA) and life cycle cost analysis (LCCA).

\section{Engineering models}

\subsection{Physical modelling}

One of the key modelling activities that is carried out when considering road pavements is related to the time-dependent temperature profiles that are created within their sections as a result of their exposure to the environment. Such an activity is relevant for the prediction of the structural properties of temperature-sensitive bitumen-bound mixtures and for the assessment of possible urban heat island effects in urban centers. Relevant factors that need to be taken into account in the process of modelling include the thermal properties of paving materials (e.g. absorptivity, thermal conductivity, thermal emissivity, specific heat) and ambient conditions (e.g. sunlight, wind, air temperature).

Previous studies described in the literature indicate that during the summer season, pavement temperatures in the Gulf region can frequently reach, and sometimes exceed, $70{ }^{\circ} \mathrm{C}$ (Al-Abdul Wahhab et al., 1997, Sirin et al., 2017). Such an occurrence leads to a significant stiffness reduction in the top asphalt layers that needs to be taken into account both in the selection of component materials (aggregates and bituminous binders), in the mix design and performance-related characterization of the resulting asphalt mixes, and in the structural design of the pavement systems. In the worst-case scenario, high temperature conditions can ultimately lead to the formation of surface depressions (rutting), to the development of local defects, and to overall pavement failure. In the context of a sustainable approach to pavement design and construction, it is essential to minimize the frequency of occurrence of these phenomena, thereby optimizing the use of physical and financial resources.

For the State of Qatar, the temperature-related issues outlined above are duly being considered by Ashghal that is supporting the use of a set of continuously updated standards and procedures that, whenever applicable, rely upon appropriate prediction models. 
Santagata, E.; Tsantilis, L.; Brignone Aimonetto, I.; Marchiando, M.; Idris, O.E.M.; Ali, M.H.M.M.; Al-Marri, A.M.
Engineering models for the design of long-lasting, sustainable, cost-efficient and climate-responsive pavements for Ashghal road projects in Qatar

According to the model initially developed by Solaimanian and Kennedy (1993) and later adopted within the SHRP project (Kennedy et al., 1994), maximum pavement surface temperature can be expressed as a function of maximum air temperature by considering the energy balance that occurs at the pavement surface as a result of heat flow associated to various components (direct solar radiation, atmospheric radiation, convection energy, conduction energy and emitted radiation energy). In analytical terms this is expressed by means of the following equation:

$1331 \cdot \alpha \cdot \tau_{a}^{\frac{1}{\cos Z}} \cdot \cos Z+\varepsilon_{a} \cdot \sigma \cdot T_{a(\max )}^{4}-h_{c} \cdot\left(T_{s(\max )}-T_{a(\max )}\right)-164 \cdot k-\varepsilon \cdot \sigma \cdot T_{s(\max )}{ }^{4}=0$

where: $\alpha$ is the pavement surface absorptivity, $\tau_{a}$ is the heat transmission coefficient for air, $Z$ is (latitude $-20^{\circ}$ ), $\varepsilon$ is the pavement surface emissivity, $\sigma$ is the Stefan-Boltzmann constant, $h_{c}$ is the surface coefficient of heat transfer, $k$ is the thermal conductivity coefficient, $T_{a(\max )}$ is maximum air temperature (in $\mathrm{K}), T_{s(\max )}$ is maximum pavement surface temperature (in $\mathrm{K}$ ).

As suggested by Huber (1994), equation (1) can be simplified by assuming default values of most of the indicated parameters, thereby obtaining the following expression:

$T_{s(\max )}=T_{a(\max )}+0.00618 \cdot \varphi^{2}+0.2289 \cdot \varphi+24.4$

where: $T_{s(\max )}$ is maximum pavement surface temperature (in ${ }^{\circ} \mathrm{C}$ ), $T_{a(\max )}$ is maximum air temperature (in $\left.{ }^{\circ} \mathrm{C}\right), \varphi$ is latitude (in degrees).

$T_{s(\max )}$ values obtained by means of equation (2) can be converted into maximum temperature values occurring in the pavement at any depth from the surface by means of the Integrated Model of Climatic Effects on Pavements developed by Lytton et al. (1993) for the U.S. Federal Highway Administration. The final analytical expression that results from such a combination is the following:

$T_{d(\max )}=\left[T_{s(\max )}+17.8\right] \cdot\left[1-2.48 \cdot\left(10^{-3}\right) \cdot d+1.085 \cdot\left(10^{-5}\right) \cdot d^{2}-2.441 \cdot\left(10^{-8}\right) \cdot d^{3}\right]-17.8$

where: $d$ is the depth from the pavement surface (in $\mathrm{mm}$ ), $T_{d(\max )}$ is maximum pavement temperature at depth $d$ (in $\left.{ }^{\circ} \mathrm{C}\right), T_{s(\max )}$ is maximum pavement surface temperature (in ${ }^{\circ} \mathrm{C}$ ).

Within the original SHRP framework, equation (3) is employed for the calculation of maximum pavement design temperatures at specific depths from the surface, which in turn are compared to the upper limiting temperature of the performance grade (PG) associated to employed bituminous binders. Such a limiting temperature is derived from the results of laboratory rheological tests that are carried out on binder samples in temperature, loading and ageing conditions that are representative of those that are encountered in the pavements during their service life.

In the case of Qatar, past studies have shown that local environmental conditions require the use of PG76-10 binders, which by definition are appropriate for maximum pavement design temperatures up to $76{ }^{\circ} \mathrm{C}$. This type of requirement is included in the current version of Qatar Construction Specifications (QCS 2014) for the case of polymer-modified binders (PMBs). Furthermore, this same requirement is maintained for the acceptance of crumb rubber modified binders (CRMB) that have been recently introduced in the Country in order to provide a solution to the management of end-of-life tires and to optimize the long-term efficiency of investments for road construction and maintenance (RPD, 2018; QSD, 2018a; QSD, 2018b). Thus, they represent a key asset in the overall perspective of sustainability.

In addition to those described by equations (1) to (3), other pavement temperature analytical models are used in Qatar in the context of mechanistic pavement design. This is required to be performed in accordance with the most recent version of the Qatar Highway Design Manual (QHDM 2015), integrated by the amendments and guidelines contained in Interim Advice Note 101 (Ashghal, 2015). In this document it is indicated that the characteristic temperature of each asphalt layer to considered in the 
Santagata, E.; Tsantilis, L.; Brignone Aimonetto, I.; Marchiando, M.; Idris, O.E.M.; Ali, M.H.M.M.; Al-Marri, A.M.
Engineering models for the design of long-lasting, sustainable, cost-efficient and climate-responsive pavements for Ashghal road projects in Qatar

design process should be computed at its centre by making use of the so-called BELLS2 model (Lukanen et al., 2000) given by the following expression:

$$
\begin{aligned}
T_{d}= & 2.78+0.912 \cdot T_{s(a v g)}+ \\
& +\left[\log _{10}(d)-1.25\right] \cdot\left[-0.428 \cdot d+0.553 \cdot T_{(1-\text { day })}+2.63 \cdot \sin \left(\frac{h r_{18(11-05)}-15.5}{18} \cdot 2 \pi\right)\right]+ \\
& +0.027 \cdot d \cdot \sin \left(\frac{h r_{18(09-03)}-15.5}{18} \cdot 2 \pi\right)
\end{aligned}
$$

where: $T_{d}$ is pavement temperature at depth $\mathrm{d}$ (in ${ }^{\circ} \mathrm{C}$ ), $T_{s(\text { avg) }}$ is average pavement surface temperature (in ${ }^{\circ} \mathrm{C}$ ), $d$ is the depth from the pavement surface (in $\mathrm{mm}$ ), $T_{(1-\text { day })}$ is average air temperature on the previous day (in $\left.{ }^{\circ} \mathrm{C}\right), \mathrm{hr}_{18(11-05)}$ is the time of day in the 24 hours clock system converted to decimal form (considering only the times from 11:00 am to 05:00 am), $\mathrm{hr}_{18(09-03)}$ is the time of day in the 24 hours clock system converted to decimal form (considering only the times from 09:00 am to 03:00 am).

The $T_{s(a v g)}$ value to be considered in equation (4) is calculated as the average of the maximum pavement surface temperature deriving from equation (2) and the minimum pavement surface temperature $T_{s(\mathrm{~min})}$ obtained from the following expression proposed by McGennis et al. (1995):

$T_{s(\min )}=0.859 \cdot T_{a(\min )}+1.7$

where: $T_{a(\min )}$ is the minimum air temperature (in ${ }^{\circ} \mathrm{C}$ ).

It should be mentioned that pavement design procedures previously referred to in Qatar and contained in the 1997 version of QHDM (QHDM 1997), indicated a single reference temperature for asphalt layers, set equal to $40^{\circ} \mathrm{C}$, with a corresponding design value of the equivalent elastic modulus equal to 1,000 $\mathrm{MPa}$. This is a very conservative hypothesis that does not capture the specific characteristics of temperature profiles and does not allow the distinction between different types of asphalt mixes, including those containing recycled component materials. Thus, the improved procedures illustrated above, supported by the described temperature models and by the results of experimental tests carried out on asphalt mixes for the evaluation of their mechanical properties, allow designers to better optimize the cross sections of pavement systems. This is a crucial aspect in the context of a sustainable approach to pavement engineering in the State of Qatar, that deserves to be supported by further research activities for fine-tuning and validation purposes.

With respect to the issue of heat island effects, the analytical models discussed above can serve as a basis for the identification of materials and technologies that reduce pavement surface temperature and associated heat flows (Qin, 2015). In such a context, current research activities worldwide are focusing on the concept of "cool pavements" that are characterized by specific surface and bulk properties that have a direct influence on the absorption (or reflection) of solar radiation, on conduction phenomena and on surface convection (Pacheco-Torgal et al., 2020).

In the State of Qatar, cool pavements are still in the development phase and the various possibilities of implementation still need to be fully explored. Nevertheless, trial sections have already been constructed (e.g. the so-called "blue pavement" on Abdullah bin Jassim Street by Souq Waqif) and specific investigations on this topic are being carried out in the Ashghal Center for Research \& Development (ACRD). Experimental and modelling activities are also being carried out for energy-harvesting purposes, since the hot and arid climate of the Gulf Region encourages this type of research action. 
Santagata, E.; Tsantilis, L.; Brignone Aimonetto, I.; Marchiando, M.; Idris, O.E.M.; Ali, M.H.M.M.; Al-Marri, A.M.
Engineering models for the design of long-lasting,

sustainable, cost-efficient and climate-responsive pavements for Ashghal road projects in Qatar

\subsection{Environmental modelling}

The environmental modelling of road pavements focuses on consumption of resources, production of emissions and generation of impacts associated with human health and land occupation. These phenomena are collectively analysed within a common framework, that allows the quantification of all the environmental burdens related to road pavement construction, maintenance and rehabilitation operations, considering the relative influence of materials, transport, and processes.

LCA is an environmental analysis technique which relies on a standardized method introduced by the International Standards Organization (EN ISO 14040:2006; ISO 14044:2006). Such method is composed of four phases, that are: i) goal and scope definition; ii) life cycle inventory analysis; iii) life cycle impact assessment; and iv) interpretation.

In the first phase of "goal and scope definition", the objective of the study, the intended application, the system boundaries and the reference functional unit are specified. The "inventory phase" is dedicated to the collection of data for environmental inputs and outputs related to each process included in the system boundaries. The phase of "impact assessment" represents the core of the LCA process, in which engineering models are used to convert inventory data into environmental impacts. The last phase of "interpretation" is finalized to draw conclusions and recommendations in accordance with the goal and scope of the LCA study.

When focusing on road pavements, different levels of LCA modelling can be defined depending on the stages that are included in the study. When the entire pavement life is considered in the analysis, from raw materials extraction to final disposal, a "cradle-to-grave" approach is adopted. However, a restriction of the system boundaries can lead to "cradle-to-the-end", "cradle-to-laid" and "cradle-to-gate" approaches when final disposal, use/maintenance and construction stages are progressively excluded from the system boundaries (Huang and Parry, 2014). A "cradle-to-cradle" approach can be also taken into consideration in the case of recycling of the materials composing the pavement structure.

In the specific case of the road infrastructures of the State of Qatar, LCA studies can be successfully employed to support the adoption of innovative (and more sustainable) pavement solutions that include recycled materials (Farina et al., 2017). These are currently being promoted as part of the "Ashghal Recycling Initiative" (Ashghal 2018) that has led to the centralization of the collection and storage of usable recycled materials, to the identification of new technical requirements to be introduced in the upcoming updated version of QCS, and will eventually produce adjustments to be embedded in the current tender and contract system. The ultimate goal of the initiative is to allow in the near future the reuse of $100 \%$ of recycled materials in pavement construction in Qatar.

Current LCA activities that are being carried out with respect to recycling opportunities in Qatar are focusing on the identification of reliable inventory data and on the trial use of available LCA software products. Preliminary findings drawn from this phase of development are synthesized in the following, where the discussed data refer to the life-cycle comparison between a standard pavement cross section (scenario 1) and an alternative one containing reclaimed asphalt pavement (RAP) in its base course layers (scenario 2). In both cases, the cross section is composed of $5 \mathrm{~cm}$ asphalt wearing course, $7 \mathrm{~cm}$ asphalt base course class $B, 10 \mathrm{~cm}$ asphalt base course class $A, 15 \mathrm{~cm}$ granular sub-base, and $30 \mathrm{~cm}$ granular capping layer (with a CBR of $25 \%$ ). As indicated in the design charts of QHDM 1997, such a cross section is compatible with traffic class T3, corresponding to a predicted design traffic comprised between 2 and 5 million standard axles (with a load of $80 \mathrm{kN}$ ).

Asphalt mixes composing the top layers of the two cross sections were considered to have composition and volumetric characteristics that satisfy the requirements of QCS. While scenario 1 entailed the use of $100 \%$ virgin aggregates, in the case of scenario 2 a dosage of $15 \%$ RAP was hypothesized in the two base 
Santagata, E.; Tsantilis, L.; Brignone Aimonetto, I.; Marchiando, M.; Idris, O.E.M.; Ali, M.H.M.M.; Al-Marri, A.M.
Engineering models for the design of long-lasting, sustainable, cost-efficient and climate-responsive pavements for Ashghal road projects in Qatar

courses (class $A$ and $B$ ). This is consistent with the recommendations that will be included in the future version of QCS as a result of the laboratory investigations and field trials carried out during the "QA/QC Pavement Consultancy Services" project.

LCA modelling was performed by making use of the "PaLATE" tool (Pavement Life Cycle Assessment Tool for Environmental and Economic Effects), with an appropriate modification of some of its embedded algorithms. According to a "cradle-to-laid" approach, the LCA system boundaries included raw materials' sourcing and production, national and international road transport, and pavement construction. Environmental impacts related to the use stage, maintenance, final pavement demolition and end-of-life disposal, were not considered since they are equivalent for both scenarios. The functional unit employed in the analysis consists in $1 \mathrm{~km}$ of a single lane.

With respect to the inventory phase, default PaLATE data were updated on the basis of recent analyses found in the sector literature and of data directly collected from road construction contractors. Road mode of transport was used to cover all national travel distances, while both road and maritime modes of transport were used for international travels. It should be underlined that the system boundaries of the analysis did not include international barge transport, that deserves a separate evaluation. Considered hauling vehicles, production plants and field construction equipment were of the standard type, and were associated to representative values of engine power, fuel consumption and productivity.

Ten impact categories were considered in the analysis. These are global warming potential (GWP, expressed in terms of carbon dioxide equivalent $\left.\mathrm{CO}_{2 e q}\right)$, water consumption, energy, nitrogen oxides $\left(\mathrm{NO}_{\mathrm{x}}\right)$, particulate matter $\left(\mathrm{PM}_{10}\right)$, carbon mono-oxide $(\mathrm{CO})$, sulphur dioxide $\left(\mathrm{SO}_{2}\right)$, heavy metals $(\mathrm{Pb}$ and $\mathrm{Hg}$ ) and generated hazardous waste (RCRA).

The relative impacts of materials production, materials road transport, and construction processes (for use of equipment), for scenario 1 (with $100 \%$ virgin aggregates in asphalt) are presented in Figure 1. When considering the initial construction stage, the most significant environmental burdens were found to derive from materials production, with lower contributions associated to transport and negligible effects related to involved processes (that never exceeded $1 \%$ ). The only exception is represented by the $\mathrm{NO}_{\mathrm{x}}$ impact category, that showed an effect of materials transport that was close to $90 \%$.

The results synthesized in Figure 1 clearly indicate that strategies for the environmental improvement of road pavement construction in Qatar should focus on the optimization of raw materials procurement and processing. In such a context, recycling initiatives are bound to be effective and should be regarded as an essential priority from the viewpoint of sustainability.

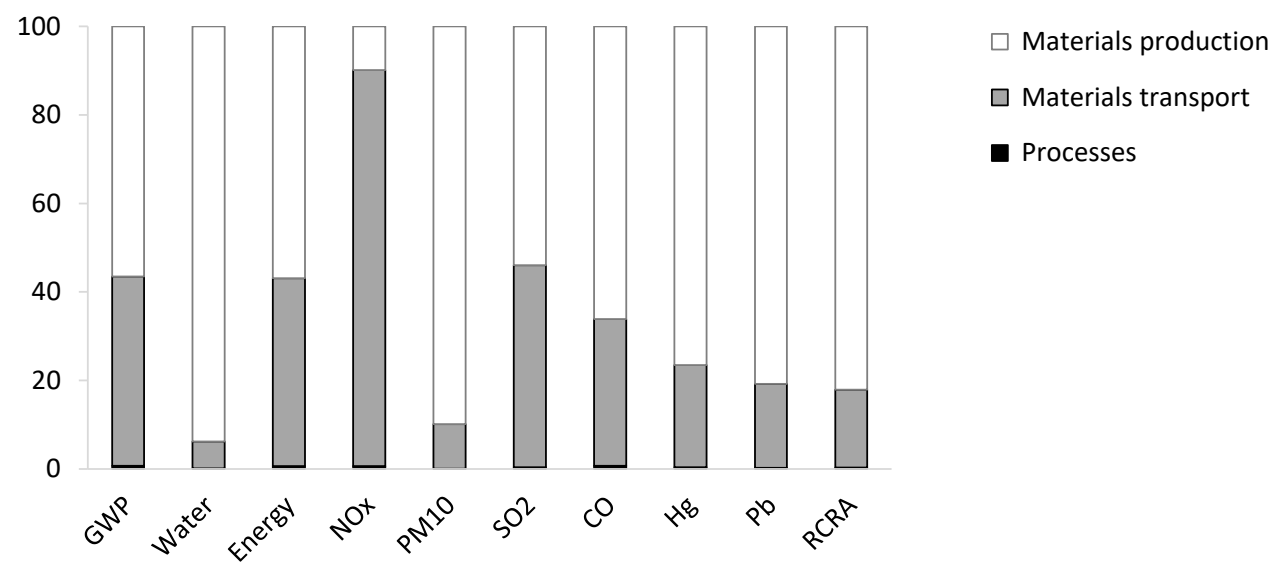

Figure 1. Relative impacts caused by materials production, materials transport and processes in pavement construction (scenario 1 with virgin materials). 
Santagata, E.; Tsantilis, L.; Brignone Aimonetto, I.; Marchiando, M.; Idris, O.E.M.; Ali, M.H.M.M.; Al-Marri, A.M.
Engineering models for the design of long-lasting, sustainable, cost-efficient and climate-responsive pavements for Ashghal road projects in Qatar

Results obtained when comparing the two considered scenarios are presented in Table 1, which also lists the absolute differences between the values of the various environmental indicators. Since in all cases there was an impact decrease when shifting from scenario 1 to scenario 2, these differences are referred to as "environmental savings".

Although the hypothesized RAP dosage was relatively low, environmental savings were definitely not negligible. For example, when considering global warming potential, water consumption and energy, the use of $15 \%$ RAP in asphalt base courses leads to a reduction of 2,619 kg of $\mathrm{CO}_{2 \mathrm{eq}}, 692 \mathrm{~kg}$ of water and 36 GJ of energy, for each $\mathrm{km}$ and lane of construction. In the context of the continuously expanding road network of the State of Qatar, these quantities translate into a massive environmental benefit. This can be further enhanced by introducing supplementary recycled products in road construction (e.g. crumb rubber, steel slag, excavated limestone) and by increasing their relative dosages.

Table 1. Environmental outputs for the two scenarios and corresponding environmental savings.

\begin{tabular}{lccc}
\hline & $\begin{array}{c}\text { Scenario 1 } \\
\text { (Virgin materials) }\end{array}$ & $\begin{array}{c}\text { Scenario 2 } \\
(15 \% \text { RAP in base })\end{array}$ & $\begin{array}{c}\text { Environmental } \\
\text { savings }\end{array}$ \\
\hline GWP [CO ${ }_{\text {eq }}$ tons] & $1.446 \mathrm{E}+02$ & $1.420 \mathrm{E}+02$ & $2.619 \mathrm{E}+00$ \\
Water [kg] & $1.053 \mathrm{E}+05$ & $1.046 \mathrm{E}+05$ & $6.923 \mathrm{E}+02$ \\
Energy [MJ] & $1.952 \mathrm{E}+06$ & $1.915 \mathrm{E}+06$ & $3.645 \mathrm{E}+04$ \\
$\mathrm{NO}_{\mathrm{x}}[\mathrm{kg}]$ & $3.690 \mathrm{E}+03$ & $3.601 \mathrm{E}+03$ & $8.860 \mathrm{E}+01$ \\
$\mathrm{PM}_{10}[\mathrm{~kg}]$ & $6.371 \mathrm{E}+03$ & $6.315 \mathrm{E}+03$ & $5.595 \mathrm{E}+01$ \\
$\mathrm{SO}_{2}[\mathrm{~kg}]$ & $4.343 \mathrm{E}+02$ & $4.266 \mathrm{E}+02$ & $7.705 \mathrm{E}+00$ \\
$\mathrm{CO}[\mathrm{kg}]$ & $8.287 \mathrm{E}+02$ & $8.181 \mathrm{E}+02$ & $1.057 \mathrm{E}+01$ \\
$\mathrm{Hg}[\mathrm{g}]$ & $3.859 \mathrm{E}+00$ & $3.836 \mathrm{E}+00$ & $2.255 \mathrm{E}-02$ \\
$\mathrm{~Pb}[\mathrm{~g}]$ & $1.961 \mathrm{E}+02$ & $1.921 \mathrm{E}+02$ & $4.043 \mathrm{E}+00$ \\
$\mathrm{RCRA}[\mathrm{kg}]$ & $3.730 \mathrm{E}+04$ & $3.709 \mathrm{E}+04$ & $2.110 \mathrm{E}+02$ \\
\hline
\end{tabular}

\subsection{Economic modelling}

The construction and maintenance of road pavements is associated to financial investments that may be quite significant in Countries characterized by a rapidly expanding road network. This is certainly the case of the State of Qatar, where a remarkable enhancement of connectivity opportunities has occurred as a result of the "Expressway" and "Local Roads and Drainage" programs. Although resources have been continuously available, in the context of a sustainable approach a certain emphasis is currently been given to the identification of investment priorities and to the reduction of costs. These issues are mainly addressed at the strategic and political level, but they may also be considered by means of pavement engineering models that combine performance predictions with relevant economic factors.

LCCA models are used worldwide to support transportation agencies in the overall management of pavement construction and maintenance operations (Babashamsi et al., 2016). They are based on well-founded principles of economic analysis, incorporating initial and discounted future costs for agencies and users throughout the considered analysis period (Wall and Smith, 1998). Employed procedures may differ with respect to the scale at which they are applied (network or project), to the employed economic indicators, and to the width and variety of costs that are taken into account in calculations.

Preliminary LCCA analyses performed during the "QA/QC Pavement Consultancy Services" project have been based on the calculation of the net present value (NPV), that represents the present discounted monetary value of expected net benefits. For such a purpose, values to be assigned to costs and benefits have been derived from the analysis of the economics of the local supply chain. These have been then 
Santagata, E.; Tsantilis, L.; Brignone Aimonetto, I.; Marchiando, M.; Idris, O.E.M.; Ali, M.H.M.M.; Al-Marri, A.M.
Engineering models for the design of long-lasting, sustainable, cost-efficient and climate-responsive pavements for Ashghal road projects in Qatar

fitted to the timeline of analysis by making use of appropriate pavement performance predictions and by hypothisizing discount rate values consistent with ongoing local and international trends. The approach to LCCA has been kept at a deterministic level, since a more complex statistical framework, although extremely valid and powerful, requires the availability of a more solid and mature database (Ozbay et al., 2003).

The most basic equation that is referred to for the calculation of NPV is the following, in which routine maintenance and user costs are not considered:

$N P V=C_{0}+\sum_{i=1}^{m} M_{i} \cdot\left(\frac{1}{1+r}\right)^{n_{i}}-S \cdot\left(\frac{1}{1+r}\right)^{T}$

where: $C_{0}$ is the initial cost of construction, $M_{i}$ is the cost the the $\mathrm{i}$-th maintenance or rehabilitation activity, $m$ is the number of the maintenance or rehabilitation activities, $n_{i}$ is the year of expenditure of the $i$-th maintenance or rehabilitation activity, $S$ is the savage value at the end of the analysis period, $T$ is the analysis period (in years).

In the State of Qatar, LCCA analyses have been considered of premium importance in the context of the "Ashghal Recycling Initiative" (Ashghal 2018), since they represent a fundamental component for the assessment of innovative pavement solutions. Preliminary findings drawn from the early phases of use of this type of analysis are briefly shown in the following, where the presented data refer to the case of the use of crumb rubber as a bitumen modifier in asphalt mixes for flexible road pavements. Such a technological solution has been launched by Ashghal, that in 2018 has enforced the use of CRMBs in lieu of PMBs for all projects overseen by the Road Projects Department (RPD) (RPD, 2018).

Two different scenarios were considered in the analysis. The first one (scenario A) corresponds to the market dynamics that were in place in 2018, when CRMBs were considered as "non-conventional" extremely expensive binders. The second one (scenario B) is representative of the local situation expected to occur in Qatar after the approval of technical specifications for the production and assessment of CRMBs. This obviously corresponds to lower costs for contractors and administrations, and should be regarded as the "regime condition" that will hopefully reached in the medium- and long-term. In both scenarios the use of CRMBs was considered either in the wearing course only, or both in the wearing course and in the underlying base course. As in the case of LCA modelling (see section 3.2), calculations were carried out for $1 \mathrm{~km}$ of a single lane. Frequency of maintenance activities was considered to be a direct function of the type of employed binder.

Results obtained in the analysis described above are synthesized in Table 2, where they are expressed in terms of percentage NPV savings with respect to the standard pavement cross section with 60/70 penetration bitumen. It can be clearly observed that savings are in all cases non-negligible, and that a significant optimization of investments can be obtained when using CRMBs.

Table 2. LCCA savings (in \%) for different scenarios in the case of the use of CRMBs in asphalt layers.

\begin{tabular}{lcccc}
\hline & \multicolumn{2}{c}{$\begin{array}{c}\text { Scenario A } \\
\text { (Market 2018) }\end{array}$} & \multicolumn{2}{c}{$\begin{array}{c}\text { Scenario B } \\
\text { (At regime) }\end{array}$} \\
\hline CRMBs in: & $\begin{array}{c}\text { Base and } \\
\text { wearing }\end{array}$ & $\begin{array}{c}\text { Base } \\
\text { only }\end{array}$ & $\begin{array}{c}\text { Base and } \\
\text { wearing }\end{array}$ & $\begin{array}{c}\text { Base } \\
\text { only }\end{array}$ \\
\hline On NPV of binder (\%) & 6.7 & 10.0 & 18.9 & 17.4 \\
On NPV of mix (\%) & 12.1 & 13.8 & 25.0 & 23.0 \\
On NPV of construction (laid material) (\%) & 12.9 & 14.6 & 23.3 & 22.0 \\
On NPV of pavement (\%) & 12.8 & 14.5 & 22.9 & 21.7 \\
\hline
\end{tabular}


Santagata, E.; Tsantilis, L.; Brignone Aimonetto, I.; Marchiando, M.; Idris, O.E.M.; Ali, M.H.M.M.; Al-Marri, A.M.
Engineering models for the design of long-lasting, sustainable, cost-efficient and climate-responsive pavements for Ashghal road projects in Qatar

\section{Conclusions}

This paper provides an overview of some of the pavement-related engineering models that are being employed as part of the studies coordinated by the Quality and Safety Department (QSD) of Ashghal while taking into account local climatic conditions, availability of resources and economic constraints.

Results provided in the paper show that the use of the illustrated models may be of significant value for the development of future infrastructures in the State of Qatar. However, it should be underlined that such a results can be achieved when the use of engineering models is supported by adequate input data derived from either experimental investigations or detailed preliminary evaluations. Finally, it should be emphasized that although ongoing studies in Qatar are being tailored for local implementation, it is envisioned that they may be fruitfully shared with the international community and that their results may be kept into consideration in other similar scenarios.

\section{Acknowledgements}

Activities documented in this paper were carried out as part of the 18-month extension period of the "QA/QC Pavement Consultancy Services" project IA/10-11/S/013/G, contract P2012/27. The support of the managing and technical staff of the Public Works Authority of the State of Qatar is gratefully acknowledged. In particular, the ANAS team has worked in close cooperation with the staff of the Quality \& Safety Department (QSD) of Ashghal.

\section{References}

Al-Abdul Wahhab, H.I., Asi, I.M., Al-Dubabe, I.A., Farhat Ali M. (1997). Development of performancebased bitumen specifications for the Gulf countries. Construction and Building Materials, 11(1), 15-22.

Ashghal (2015). Interim Advice Note No. 101 (IAN 101). Doha, Qatar, 01/10/2015.

Ashghal (2018). Roadmap for implementation of Ashghal Initiative of recycling in construction projects (Circular No (69)). Doha, Qatar, 09/05/2018.

Babashamsi, P., Yusoff, N.I., Ceylan, H., Nor, N.G., Jenatabadi, H.S. (2016). Evaluation of pavement life cycle cost analysis: Review and analysis. International Journal of Pavement Research and Technology, 9, 241-254.

Farina, A., Zanetti, M.C., Santagata, E., Blengini, G.A. (2017). Life cycle assessment applied to bituminous mixtures containing recycled materials: crumb rubber and reclaimed asphalt pavement. Resources, Conservation and Recycling, 117(B), 204-212.

EN ISO 14040:2006. Environmental management - Life cycle assessment - Principles and framework.

Huang, Y., Bird, R., Heidrich, O. (2007). A review of the use of recycled solid waste materials in asphalt pavements. Resources Conservation and Recycling, 52(1), 58-73.

Huang, Y., Parry, T. (2014). Life cycle assessment of pavements, in Gopalakrishnan, K., Steyn, W.J., Harvey, J. (eds.) (2014) Pavement Life Cycle Assessment. Climate change, energy, sustainability and pavements. Berlin: Springer.

Huber, G.L. (1994). Weather Data Base for the Superpave Mix Design System. Strategic Highway Research Program., Report SHRP-A-648A. Strategic Highway Research Program, National Research Council. Washington, D.C.

ISO 14044:2006. Environmental management - Life cycle assessment - Requirements and guidelines. 
Santagata, E.; Tsantilis, L.; Brignone Aimonetto, I.; Marchiando, M.; Idris, O.E.M.; Ali, M.H.M.M.; Al-Marri, A.M.
Engineering models for the design of long-lasting, sustainable, cost-efficient and climate-responsive pavements for Ashghal road projects in Qatar

Kennedy, T.W., Huber, G.A., Harrigan, E.T., Cominsky, R.J., Highes, C.S., von Quintus, H., Moulthrop, J.S. (1994). Superior Performing Asphalt Pavements (Superpave): the Product of the SHRP Asphalt Research Program. Report SHRP-A-410. Strategic Highway Research Program, National Research Council, Washington, D.C.

Lukanen E.O., Stubstad, R.N., Briggs, K. (2000). Temperature predictions and adjustment factors for asphalt pavement. Report FHWA-RD-98-085. Federal Highway Administration, McLean, VA, U.S.A.

Lytton, R.L., Pufahl, D.E., Michalak, C.H., Liang, H.S., Dempsey, B.J. (1993). An Integrated Model of the Climatic Effects on Pavements. Report FHWA-RD-90-033. Federal Highway Administration, McLean, VA, U.S.A.

McGennis, R.B., Anderson, R.M., Kennedy, T.W., Solaimanian, M. (1995). Background of Superpave asphalt mixture design and analysis. Report FHWA-SA-95-003, Federal Highway Administration, Washington, D.C., U.S.A.

Ozbay, K., Parker, N.A., Jawad, D., Hussain, S. (2003). Guidelines for Life Cycle Cost Analysis. Report FHWA-NJ-2003-012. Federal Highway Administration, Washington, D.C., U.S.A.

Pacheco-Torgal, F., Amirkhaninan, S., Wang, H., Schlangen, E. (2020). Eco-efficient pavement construction materials. First edition. Woodhead publishing series in civil and structural engineering, United Kingdom: Elsevier.

Pasetto, M, Partl, M.N., Tebaldi G. (2019). Proceedings of the 5th International Symposium on Asphalt Pavements \& Environment (APE). Switzerland: Springer Nature.

Qatar Construction Specifications (QCS) (2014). Ministry of Municipality and Environment, State of Qatar. Qatar Highway Design Manual (QHDM) (1997). Ministry of Municipality and Environment, State of Qatar. Qatar Highway Design Manual (QHDM) (2015). Ministry of Municipality and Environment, State of Qatar.

Qin, Y. (2015). A review on the development of cool pavements to mitigate urban heat island effect. Renewable and Sustainable Energy Reviews 52, pp. 445-459.

Quality and Safety Department (QSD), Ashghal (2018a). Pre-qualification of Crumb Rubber and Crumb Rubber Modified Binder Producers, Doha, Qatar, 13/12/2018.

Quality and Safety Department (QSD), Ashghal (2018b). Guidelines for Mix Design and Quality Control of CRMB Asphalt Mixes, Doha, Qatar, 18/11/2018.

Road Projects Department (RPD), Ashghal (2018). Use of Crumb Rubber in RPD projects (Circular No. (26)). Doha, Qatar, 28/10/2018.

Shandas, V., Skelhorn, C., Ferwati, S. (2020). Urban Adaptation to Climate Change the Role of Urban Form in Mediating Rising Temperatures. Springer Briefs in Environmental Science. Cham, Switzerland: Springer Nature Switzerland.

Sirin, O., Paul, D.K., Kassem, E., and Ohiduzzaman, M., 2017. Effect of aging on asphalt binders in the State of Qatar: a Case Study. Road Materials and Pavement Design, 18, 165-184.

Solaimanian, M., Kennedy, T.W. (1993). Predicting maximum pavement surface temperature using maximum air temperature and hourly solar radiation. Transportation Research Record, 1417, 11.

Walls, J., Smith, M.R. (1998). Life-Cycle Cost Analysis in Pavement Design. Interim Technical Bulletin. Federal Highway Administration, Washington, D.C., U.S.A. 